\title{
A New Genetic Based Multilayered Fuzzy Image Filter for Removing Additive Identical Independent Distribution Impulse Noise from Medical Images
}

\author{
A.Padma \\ Asst. Prof., IT \\ Velammal College \\ of Engg and Tech., Madurai.
}

\author{
Dr. R. Sukanesh \\ Professor, ECE, \\ Thiyagarajar College \\ of Engg. Madurai.
}

\author{
1. A. Santhana Vijayan \\ Lecturer ,CSE, \\ National Institute of \\ Technology, Tirchy.
}

\begin{abstract}
In this paper, we develop a multilayered genetic based fuzzy image filter, which consists of fuzzy number construction process, a fuzzy filtering process, a genetic learning process and an image knowledge base. The introduction of multilayered fuzzy systems substantially decreases the no of rules to be learnt. First, the fuzzy number construction process receives noise free image and sample images and then constructs an image knowledge base for the fuzzy filtering process. Second, the fuzzy filtering process contains a parallel fuzzy inference system, a fuzzy mean process, and a fuzzy decision process to perform the task of removing impulse noise. Finally, based on the genetic algorithm, the genetic learning process adjusts the parameters of image knowledge base. Based on the criteria of Peak Signal to Noise Ratio (PSNR), Mean Square Error (MSE) and Mean Absolute Error (MAE), Genetic based fuzzy image filter achieves a better performance.
\end{abstract}

Keywords: Parallel fuzzy inference system, fuzzy number, genetic algorithm, impulse noise, tuning, learning. Tool

Programming Languages : Math Lab Tool, Fuzzy Tool, Gene

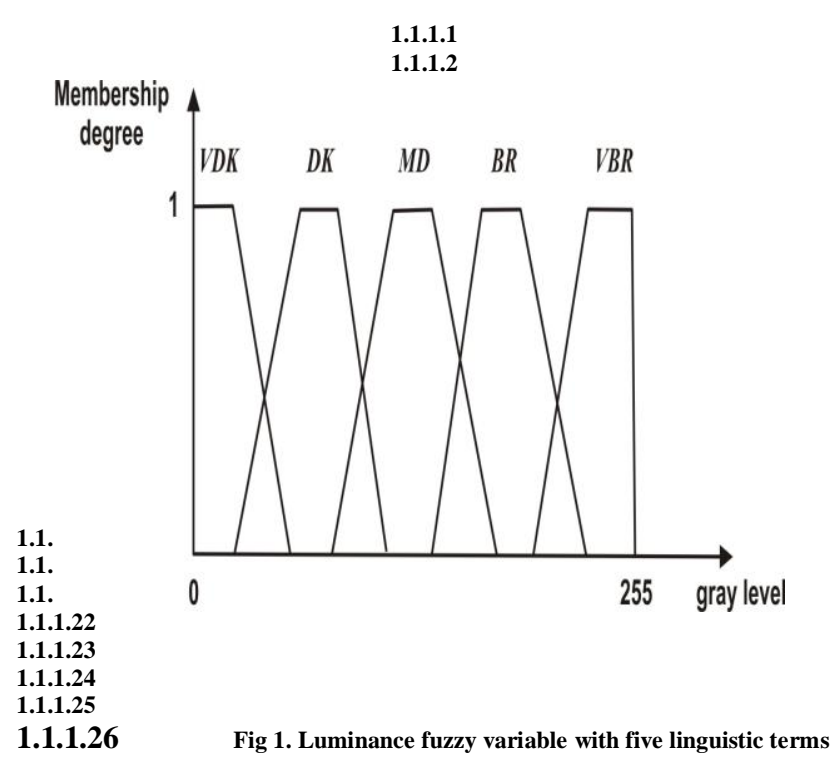

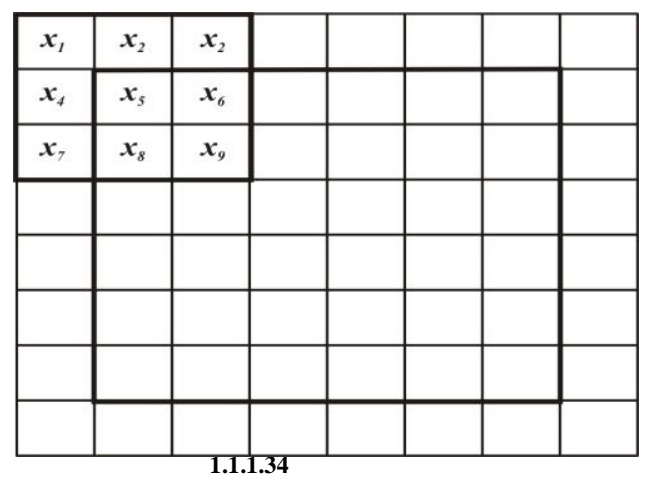

1.1.1.35 Fig 2. An 8- neighborhood

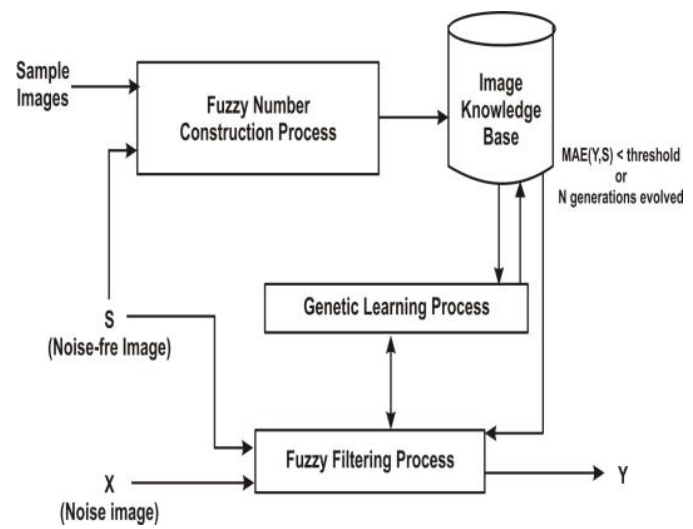

Fig 3. Structure of GBFIF 


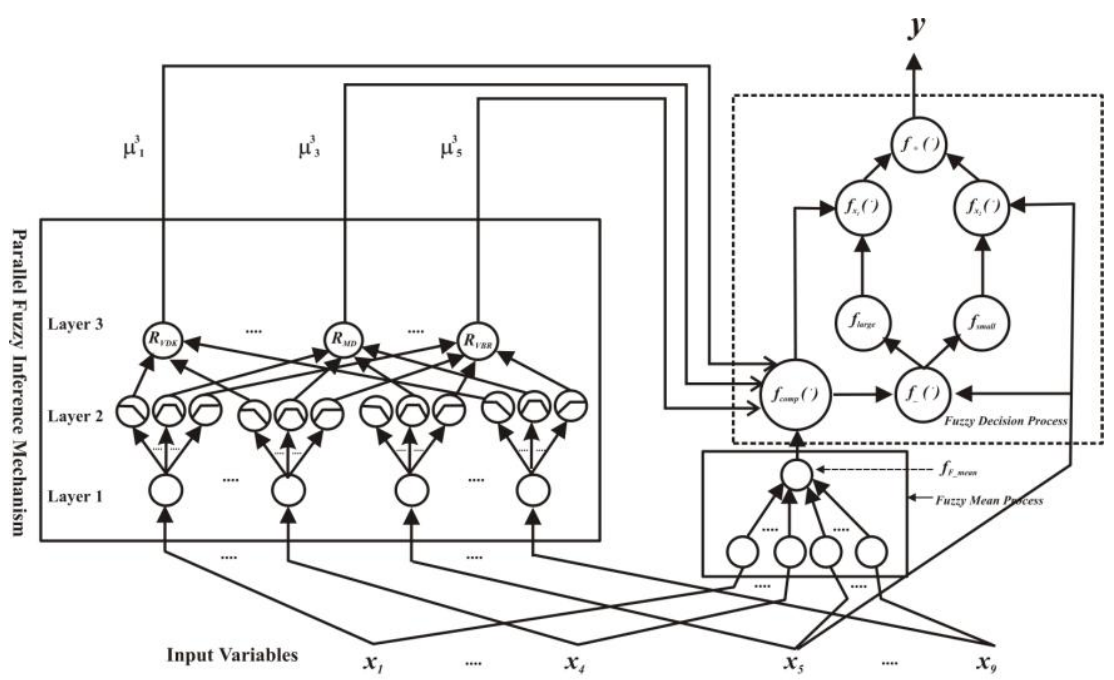

Fig. 4 Architecture of the fuzzy filtering process

\section{INTRODUCTION}

Now a days, many image processing algorithms cannot work well in a noisy environment, therefore the image filter is used as a preprocessing module for highly corrupted images or noisy images. A no. of approaches have been developed for impulse noise removal.

The Median Filter [1] can achieve good performance for low corrupted images but it will not work efficiently, when the noise rate is above 0.5. The center weighted Median Filter[2] is a special case of WM filter uses a set of parameters to control the filtering performance in order to preserve more signal details. The novel switching based Median 'Filter with fuzzy set concept [3] called the Noise Adaptive Soft Switching Median [NASM] filter to achieve a better performance in removing impulse noise. The Median Rational Hybrid Filter [ MRHF] [4] that is based on the CWM filter for removing additive impulse noise. The proposed signal dependent rank ordered mean [SDROM] [5] filter uses highly corrupted images while preserving details and features. The Weighted Fuzzy Mean Filter[6] has a better ability to remove high impulse noise, when the noise rate is above 0.5.The Adaptive Weighted Fuzzy Mean Filter [AWFM][7] not only improves the filters capability in a low noisy environment but also retains its capability of processing in the heavily noisy environment. An intelligent fuzzy image filter [FIF] [8] can authentically decide the number of

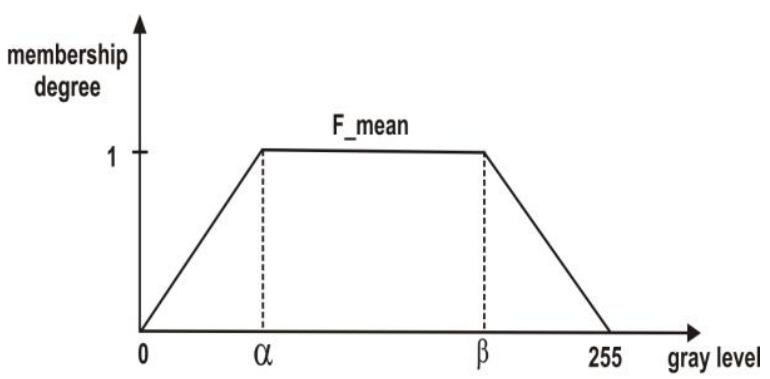

Fig. 5 Fuzzy interval F_mean for fuzzy mean process

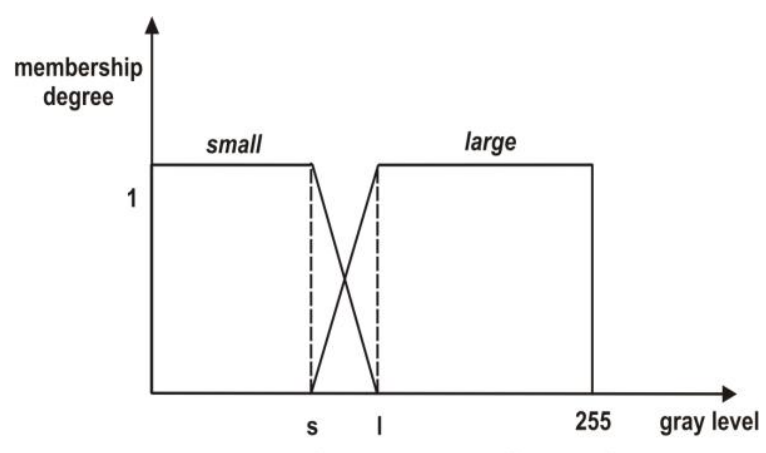

Fig. 6. Fuzzy sets for luminance difference fuzzy variable

fuzzy numbers based on image features to overcome the drawbacks of the AWFM filter. The proposed [9] hybrid neuro fuzzy filter has specifically designed to detect different patterns of noisy pixels occurring in highly corrupted images.

The proposed filters are able to yield a effective noise cancellation and to get a better performance that is better than other approaches. The Histogram[10] based fuzzy filter which is particularly effective at removing highly impulse noise while preserving image details.

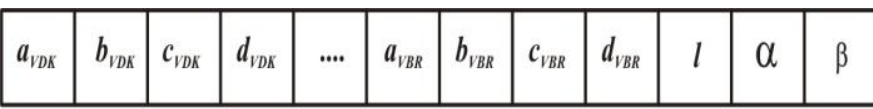

(a) $\mathrm{CS}_{a}$

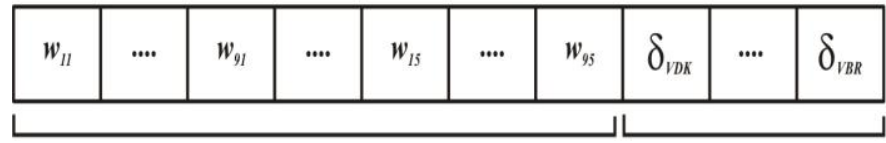

(b) $C S_{b l}$

(b) $C S_{b 2}$

Fig. 7 (a) Encoding of the parameters of fuzzy sets. (b) Encoding of the fuzzy rules (c) Encoding of the linguistic modifiers of the linguistic terms 


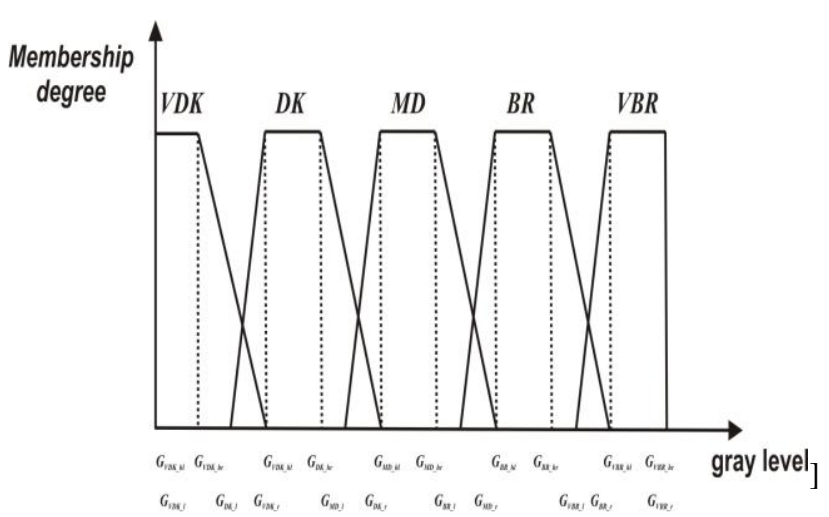

Fig. 8. Position of each linguistic term of luminance

impulse noise suppression in multichannel images. The proposed other filters such as a Decision Based, Signal Adaptive Median Filter, Classifier-Augmented Median Filter[12] fuzzy neural network filter has the ability to remove impulse noise from corrupted images.

In this paper, we propose a genetic based multilayered fuzzy image filter (GBFIF] to remove additive identical independent distribution impulse noise from highly corrupted images. The proposed filter consists of a fuzzy filtering process, a genetic learning process and an image knowledge base. First, the fuzzy number construction process receives sample images or the noise free image and then constructs the image knowledge base for the fuzzy filtering process. Second, the fuzzy filtering process contains a parallel fuzzy inference mechanism, a fuzzy mean process, and a fuzzy decision process to perform the task of noise removal.

Finally, the genetic learning process adjusts the parameters as an image knowledge base on the genetic algorithm. We will apply the genetic learning approach proposed [13] to tune the parameters of the membership functions for removing additive impulse noise from highly corrupted images. In section 2, we propose the structure of genetic based fuzzy image filter. The algorithm for the fuzzy number construction process is presented in this section. Section 3, describes the parallel fuzzy inference mechanism for the fuzzy filtering process. Section 4, focuses on the genetic learning process for GBFIF. The experimental results for GBFIF are described in section 5. Finally section 6 contains conclusion.

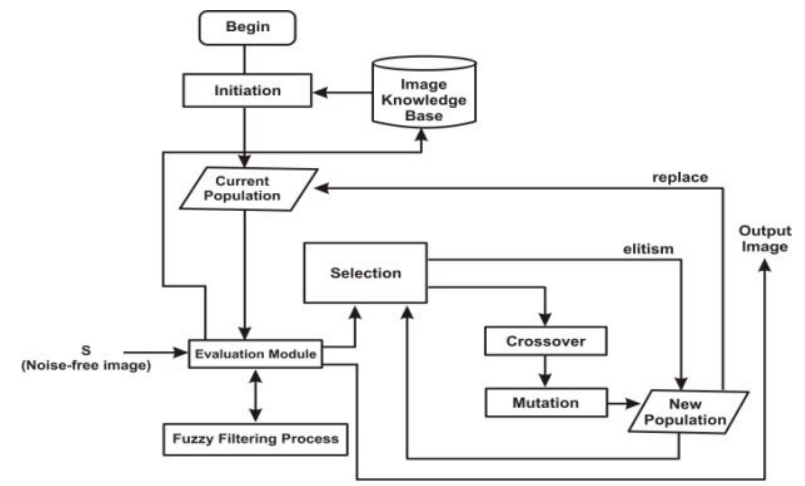

Fig. 9 Structure of Genetic learning process

\section{STRUCTURE OF GENETIC BASED MULTILAYERED FUZZY IMAGE FILTER}

We propose a Genetic based multilayered fuzzy image filter to remove impulse noise from highly corrupted images. Fig. 3 shows the structure of Genetic based multilayered fuzzy image filter

There are 3 main processes, including a fuzzy number construction process, a fuzzy filtering process, and a genetic learning process. In addition, the image knowledge base should be constructed before performing the fuzzy filtering process, we use the trapezoidal function to be membership functions of fuzzy sets. Equation (1) denotes the membership function $f_{A}(x)$ of fuzzy set $A$

$$
f_{A}(x)= \begin{cases}0, & x<a_{A} \\ \frac{\left(x-a_{A}\right)}{\left(b_{A}-a_{A}\right)}, & a_{A} \leq x<b_{A} \\ 1, & b_{A} \leq x<c_{A} \\ \frac{\left(d_{A}-x\right)}{\left(d_{A}-c_{A}\right)}, & c_{A} \leq x<d_{A} \\ 0, & x \geq d_{A} .\end{cases}
$$

The trapezoidal membership function of fuzzy set $\mathrm{A}$ is denoted by the parameter set $A=\left[a_{A}, b_{A}, c_{A}, d_{A}\right]$. Fig.2 illustrates and example five linguistic terms VDK, DK, MED, BR, VBR are used to represent fuzzy luminance variable. The membership degree is a value in the range $[0,1]$ where 1 denotes free membership and ' 0 ' denotes no membership.

The image knowledge base consists of the parameters of the membership functions. In this paper, we define the five fuzzy sets for a image including Very Dark (VDK), Dark (DK), Medium (MD), Bright (BR) and Very Bright (VBR). The membership function of fuzzy sets VDK, DK, MD, BR and VBR denoted as $\mathrm{VDK}=\left[\mathrm{a}_{\mathrm{VDK}}, \mathrm{b}_{\mathrm{VDK}}, \mathrm{c}_{\mathrm{VDK}}, \mathrm{d}_{\mathrm{VDK}}\right] \mathrm{DK}=\left[\mathrm{a}_{\mathrm{DK}}, \mathrm{b}_{\mathrm{DK}}, \mathrm{c}_{\mathrm{DK}}, \mathrm{d}_{\mathrm{DK}}\right] \mathrm{MD}=$

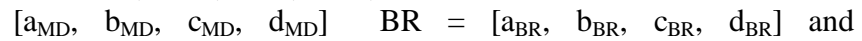
$\mathrm{VBR}=\left[\mathrm{a}_{\mathrm{VBR}}, \mathrm{b}_{\mathrm{VBR}}, \mathrm{c}_{\mathrm{VBR}}, \mathrm{d}_{\mathrm{VBR}}\right]$ respectively. The fuzzy sets describing of a noise free image can be derived from the histogram of the source image. Then the algorithm for fuzzy number construction process is as follows

\section{Algorithm for fuzzy number construction process:}

Input :

The histogram of sample image or noise free image

\section{Output:}

The parameter set of membership functions.

\section{Method:}

Step 1: Decide the overlap ranges of fuzzy sets. Let $S_{k}$ be the $k_{\text {th }}$ gray level of image $s$ and $g_{K}$ be the number of pixels with the Kth gray level in $\mathrm{S}$.

Step 1.1: Set $C_{V D K}$ be the first $S_{k}$ such that $g_{K}>0$, $\mathrm{a}_{\mathrm{DK}} \leftarrow \mathrm{C}_{\mathrm{VDK}}$

Step 1.2: Set $b_{V D R}$ be the last $S_{k}$ such that $g_{k}>0$ $\mathrm{d}_{\mathrm{BR}} \leftarrow \mathrm{b}_{\mathrm{VBR}}$ 
Step 1.3 : Set $\left.\mathrm{IR} \leftarrow\left[\mathrm{Cb}_{\mathrm{VBR}}-\mathrm{C}_{\mathrm{VDK}}\right] / 2 * \mathrm{NF}-3\right]$ Where IR denoted the value of the interval Range between $b_{V B R}$ and $C_{V D K}$, $\mathrm{N}_{\mathrm{f}}$ is the number of fuzzy sets and $\mathrm{N}_{\mathrm{f}} \geq 2$

Step 1.4 : Set $\mathrm{a}_{\mathrm{VDK}} \leftarrow 0, \mathrm{~b}_{\mathrm{VDK}} \leftarrow 0$

Step 1.5 : Set $\mathrm{C}_{\mathrm{VBR}} \leftarrow\left(2 \mathrm{xN}_{\mathrm{f}}-1\right) \mathrm{x}$ IR, $\mathrm{d}_{\mathrm{VBR}} \leftarrow \mathrm{C}_{\mathrm{VBR}}$

Step 2: Decide the parameter values of the membership function $f_{\text {VDK }}$ of fuzzy set VDK: $d_{\text {VDK }} \leftarrow \mathrm{C}_{\mathrm{VDK}}+\mathrm{IR}$

Step 3: Decide the parameter values of the membership function $f_{D K}$ of fuzzy set DK by the following steps

Step 3.1: Set $b_{\mathrm{DK}} \leftarrow \mathrm{d}_{\mathrm{VDK}}$

Step 3.2: Set $C_{D K} \leftarrow I R+B_{D K}$

Step 3.3: Set $d_{D K} \leftarrow I R+C_{D K}$

Step 4: Decide the parameter values of membership function $\mathrm{f}_{\mathrm{MD}}$ of fuzzy set MD by the following steps

Step 4.1: Set $\mathrm{a}_{\mathrm{MD}} \leftarrow \mathrm{C}_{\mathrm{DK}}$

Step 4.2: Set $\mathrm{C}_{\mathrm{MD}} \leftarrow \mathrm{d}_{\mathrm{DK}}$

Step 4.3: Set $\mathrm{C}_{\mathrm{MD}} \leftarrow \mathrm{IR}+\mathrm{b}_{\mathrm{MD}}$

Step 4.4: Set $\mathrm{d}_{\mathrm{MD}} \leftarrow \mathrm{IR}+\mathrm{C}_{\mathrm{MD}}$

Step5: Decide the parameter values of the membership function $\mathrm{f}_{\mathrm{BR}}$ of fuzzy set BR by the following steps

Step 5.1: Set $\mathrm{a}_{\mathrm{BR}} \leftarrow \mathrm{C}_{\mathrm{MD}}$

Step 5.2: Set $b_{B R} \leftarrow d_{M D}$

Step 5.3: Set $C_{B R} \leftarrow I R+b_{B R}$

Step 6: Decide the parameter values of membership function $f_{V B R}$ of fuzzy set VBR by the following

Step $6.1: \mathrm{a}_{\mathrm{VBR}} \leftarrow \mathrm{C}_{\mathrm{BR}}$

Step 7: Stop

\section{Parallel fuzzy Inference mechanism for fuzzy filtering process}

In this section, we will describe the parallel fuzzy inference mechanism for the fuzzy filtering process. We adopt the 8 neighborhood of an image for the filter. Fig 2 illustrates the neighborhood of in an image. Fig. 4 shows the fuzzy filtering process for impulse noise removal.

The fuzzy filtering process consists of a parallel fuzzy inference mechanism, a fuzzy mean process, and a fuzzy decision process. Now, we describe them as follows.

\subsection{A Parallel Fuzzy Inference Mechanism}

The structure of parallel fuzzy inference mechanism consists of three layers. There are three kinds of nodes in this structure, including the fuzzy linguistic node for the fuzzy linguistic layer, the fuzzy term node for the fuzzy term layer, and the rule node for the fuzzy rule layer. A fuzzy linguistic node represents a fuzzy variable, a fuzzy term node represents the mapping degree of the fuzzy variable. A rule node represents a rule and decides the final firing strength of that rule during inferring. Now we briefly describe each layer as follows.

Table 1 Parameters of fuzzy set constructed by GBFIF for Salt and Pepper

Noisy CT image with a Corruption Rate 0.4

\begin{tabular}{c|c|c|c|c}
\hline \multicolumn{2}{c|}{ Before tuning } & \multicolumn{2}{c}{ After tuning } \\
\hline$[$ a,b,c,d] & Fuzzy Rules & $\delta$ & {$[$ a,b,c,d] } & Fuzzy I \\
\hline$[0,0,25,55]$ & {$[1,1,1,1,1,1,1,1,1]$} & 1 & {$[0,0,15,67]$} & {$[0,1,0,1,1$,} \\
\hline$[25,55,85,115]$ & {$[1,1,1,1,1,1,1,1,1]$} & 1 & {$[35,82,83,112]$} & {$[1,1,1,1,1$,} \\
\hline$[85,115,145,175]$ & {$[1,1,1,1,1,1,1,1,1]$} & 1 & {$[84,112,134,168]$} & {$[1,1,0,0,0$,} \\
\hline $145,175,205,235]$ & {$[1,1,1,1,1,1,1,1,1]$} & 1 & {$[140,172,174,216]$} & {$[1,1,1,0,1$,} \\
\hline $205,235,255,255]$ & {$[1,1,1,1,1,1,1,1,1]$} & 1 & {$[174,229,249,255]$} & {$[0,1,0,0,1$,} \\
\hline & 72 & & & 60 \\
\hline & 25 & & & 33 \\
\hline
\end{tabular}

\subsubsection{Layer 1 ( Fuzzy linguistic layer) :}

The fuzzy linguistic nodes in this layer directly transmit input values to the next layer. If the input vector is $x=(x 1, x 2, \ldots \ldots . . . x 9)$ then $x_{i}$ is denoted as the input value of the ith pixel in the neighborhood. Then the output for this layer will be $\mu^{1}=\left(x_{11}, x_{12}, x_{13}, x_{14}, x_{15}\right),\left(x_{21}, x_{22}, x_{23}, x_{24}, x_{25}\right), \ldots\left(x_{91}, x_{92}, x_{93}\right.$,
$\left.x_{94}, x_{95}\right)$

Where $x_{i j}$ is the out value of the $j^{\text {th }}$ fuzzy linguistic term for $i^{\text {th }}$ pixel.

\subsubsection{Layer2 (Fuzzy Term Layer):}

Each fuzzy variable of the second layer is represented with a condition code. Each of the outputs of the condition code is connected to rule nodes in the third layer to constitute a condition specified in some rules. This layer is used to compute matching degrees. If the input vector of this layer is $\mu^{1}=\left(\left(\mathrm{x}_{11}, \mathrm{x}_{12}, \mathrm{x}_{13}, \mathrm{x}_{14}\right.\right.$, $\left.\mathrm{x}_{15}\right),\left(\mathrm{x}_{21}, \mathrm{x}_{22}, \mathrm{x}_{23}, \mathrm{x}_{24}, \mathrm{x}_{25}\right), \ldots \ldots . .\left(\mathrm{x}_{91}, \mathrm{x}_{92}, \mathrm{x}_{93}, \mathrm{x}_{94}, \mathrm{x}_{95}\right)$

Then the output vector will be is

$$
\begin{aligned}
\mu^{2}= & \left(\left(\mathrm{fA}_{1}\left(\mathrm{x}_{11}\right),\left(\mathrm{fA}_{2}\left(\mathrm{x}_{12}\right), \ldots \ldots\left(\mathrm{fA}_{3}\left(\mathrm{x}_{15}\right)\right),\right.\right.\right. \\
& \left(\left(\mathrm{fA}_{1}\left(\mathrm{x}_{21}\right),\left(\mathrm{fA}_{2}\left(\mathrm{x}_{22}\right), \ldots \ldots\left(\mathrm{fA}_{5}\left(\mathrm{x}_{25}\right)\right), \ldots .\right.\right.\right. \\
& \left(\left(\mathrm{fA}_{1}\left(\mathrm{x}_{91}\right),\left(\mathrm{fA}_{2}\left(\mathrm{x}_{92}\right), \ldots \ldots . .\left(\mathrm{fA}_{5}\left(\mathrm{x}_{95}\right) \ldots(3)\right.\right.\right.\right.
\end{aligned}
$$

where $f A_{j}\left(x_{i j}\right)$ is the membership degree of the jth fuzzy term for the ith pixel.

\section{Layer 3 ( Fuzzy Rule Layer):}

The third layer is called the rule layer, where each node is a rule to represent a fuzzy rule. The links in this layer are used to perform precondition matching of fuzzy logical rules. Each linguistic term of every fuzzy rule contains binary weights $\left\{\mathrm{W}_{\mathrm{ij}}\right\}$, 
where $i=1,2,3, \ldots .9$ and $j=1,2, \ldots 5$. The fuzzy inference rules are denoted as follows

Rule VDK : If ( $\mathrm{x}_{1}$ is VDK with weight $\left.\mathrm{W}_{11}\right)$ AND $\left(\mathrm{x}_{2}\right.$ is VDK with weight $\left.\mathrm{W}_{21}\right) \ldots$. AND $\left(\mathrm{x}_{9}\right.$ is VDK with weight $\left.\mathrm{W}_{91}\right)$ THEN $\mu_{1}{ }^{3}$ is VDK.

Rule VBR : If ( $\mathrm{x}_{1}$ is VBR with weight $\left.\mathrm{W}_{15}\right)$ AND $\left(\mathrm{X}_{2}\right.$ VBR with weight $\left.\mathrm{W}_{25}\right)$ AND ... AND ( $\mathrm{x}_{9}$ is VBR with weight $\left.\mathrm{W}_{95}\right)$ THEN $\mu_{5}^{3}$ is VBR.

Equation (4) shows the computing mechanism for the output $\mu_{\mathrm{i}}{ }^{3}$ of fuzzy rule Layer, where $\mathrm{j}=1, \ldots ., 5$ and we have

$$
\mu_{j}^{3}= \begin{cases}\frac{\sum_{i=1}^{n}\left(x_{i j} f_{A j}\left(x_{i j}\right)\right) \times w_{i j}}{\sum_{i=1}^{n} f_{A j}\left(x_{i j}\right) \times w_{i j}}, & \text { if }\left(\sum_{i=1}^{n} f_{A j}\left(x_{i j}\right) \times w_{i j}\right)>0 \\ 0, & \text { otherwise. }\end{cases}
$$

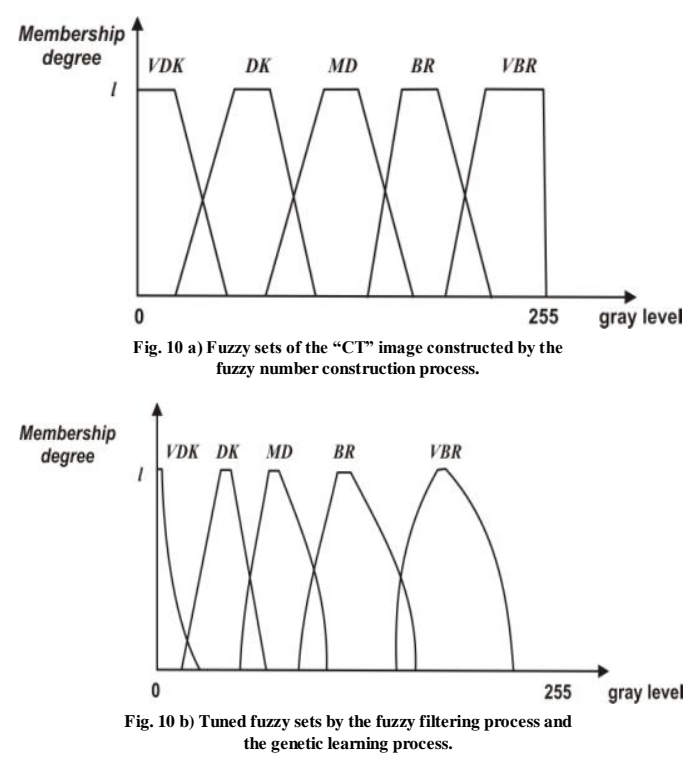

\section{B. Fuzzy Mean Process :}

The fuzzy mean process performs the fuzzy mean of input variables. Equation (5) denotes the computing process with the fuzzy interval F_mean for the fuzzy mean process.

$$
y_{\text {mean }}= \begin{cases}\frac{\sum_{i=1}^{9}\left(f_{F_{\text {-mean }}}\left(x_{i}\right) \times x_{i}\right)}{\sum_{i=1}^{9} f_{F_{\text {-mean }}}\left(x_{i}\right\rangle}, & \text { if }\left(\sum_{i=1}^{9} f_{F_{\text {m mean }}}\left(x_{i}\right)\right)>0 \\ 0, & \text { otherwise }\end{cases}
$$

Where $\mathrm{f}_{\mathrm{F}_{-} \text {mean }}=[0, \alpha, \beta, 255]$ shown in Fig.5.

\section{Fuzzy Decision Process}

In fuzzy decision process two membership functions $\mathrm{f}_{\text {large }}$ and $\mathrm{f}_{\text {small }}$ are utilized.

$$
\begin{aligned}
& \mathrm{f}_{\text {small }}=[0,0, \mathrm{~s}, 1] \\
& \mathrm{f}_{\text {large }}=[\mathrm{s}, 1,255,255] .
\end{aligned}
$$

The parameters $\mathrm{s}$ and 1 for fuzzy sets small and large are designed as follows

$$
\mathrm{S}=1 \times \mathrm{f}_{\mathrm{F}_{-} \text {mean }}\left(\mathrm{x}_{5}\right)
$$

$\mathrm{f}_{\text {small }}, \mathrm{f}_{\text {large }}$ define the detail preserving process of the filter. It basically executes full correction of large amplitude noise pulses, partial correction of median amplitude pulses, and no correction of small amplitude noise pulses. The function $\mathrm{f}-($.$) can be interpreted$ as a measure function of the correction process. If this measure is large, a full correction is allowed. If this measure is small, the correction is further reduced in order to better preserve the quality of fine details and textures

$\mathrm{F}_{\text {comp }}\left(\mu_{1}{ }^{3}, \mu_{2}{ }^{3}, \mu_{2}{ }^{3} \mu_{4}{ }^{3}, \mu_{5}{ }^{3} \mathrm{y} \mu_{\text {mean }}{ }^{3}\right)=\mu_{\mathrm{j}}{ }^{3}$

(i.e.,) $\mu_{\mathrm{j}}{ }^{3}-\mathrm{y}_{\text {mean }}$ be the minimum value for $\mathrm{j}=1,2,3,4,5$

$$
\begin{aligned}
& \mathrm{f}_{\text {comp }(.)}=\min \left(\left(\mu_{1}{ }^{3}-y_{\text {mean }}\right),\left(\mu_{2}{ }^{3}-y_{\text {mean }}\right),\left(\mu_{3}{ }^{3}-y_{\text {mean }}\right)\right. \\
& \left.\quad\left(\mu_{4}{ }^{3}-y_{\text {mean }}\right),\left(\mu_{5}{ }^{3}-y_{\text {mean }}\right)\right) \\
& \mathrm{f}_{-}(.)=\left|\mathrm{f}_{\text {comp }}(.)-\mathrm{x}_{5}\right| \\
& \mathrm{f}_{\mathrm{x} 1}(.)=\mathrm{f}_{\text {comp }}(.) \times \mathrm{f}_{\text {large }}\left(\mathrm{f}_{-}(.)\right) \\
& \mathrm{f}_{\mathrm{x} 2}(.)=\mathrm{x}_{5} \times \mathrm{f}_{\text {small }}\left(\mathrm{f}_{-}(.)\right) \\
& \mathrm{f}_{+}(.)=\mathrm{f}_{\mathrm{x} 1}(.)+\mathrm{f}_{\mathrm{x} 2}(.)
\end{aligned}
$$

\section{Genetic learning process for GBFIF}

This section will introduce the genetic learning for the fuzzy image filter. We adopt a supervised learning method based on the genetic learning for the GBFIF system. We apply the learning approach to learn the image knowledge base containing image DB stored in the parameters of fuzzy sets and image RB stored in the parameters of fuzzy rules.

Now we describe main components of image knowledge base as follows. The three components of the image knowledge base to be enclosed are the membership functions of the fuzzy variables, fuzzy rules, and the linguistic modifiers of the linguistic terms. Fig.7 shows the chromosome that composed of following sub parts $: \mathrm{CS}_{\mathrm{a}}, \mathrm{CS}_{\mathrm{b} 1}, \mathrm{CS}_{\mathrm{b} 2}$

1.CS $\mathrm{a}$ is a 23 gene that encodes the parameters of fuzzy sets.

2. $\mathrm{CS}_{\mathrm{b} 1}$ is a group of nine genes that directly encode the binary weights $\left\{\mathrm{w}_{\mathrm{ij}}\right\}$ where $\mathrm{i}=1 \ldots 9$ and $\mathrm{j}=1 \ldots .5$ for of the set of binary weights.

\section{Fuzzy Rules:}

Rule VDK : IF (X3 IS VDK AND X4 IS VDK AND X6 IS VDK) THEN $\mu_{1}^{3}$ IS VDK

Rule VBR : IF (X2 IS VBR AND X3 IS VBR AND X6 IS VBR AND X8 IS VBR ) THEN $\mu_{5}^{3}$ IS VBR

3. $\mathrm{CSb}_{2}$ is a five gene that encodes the linguistic modifiers of the linguistic terms. 
The factors of the luminance are the fuzzy linguistic terms VDK,DK,MD,BR AND VBR. In this paper, we define the encoding restrictions for the fuzzy variable as follows

$$
\begin{aligned}
& \mathrm{a}_{\mathrm{VDK}} \leq \mathrm{b}_{\mathrm{VDK}} \leq \mathrm{c}_{\mathrm{VDK}}<\mathrm{d}_{\mathrm{VDK}} \\
& \mathrm{a}_{\mathrm{DK}} \leq \mathrm{b}_{\mathrm{DK}} \leq \mathrm{c}_{\mathrm{DK}}<\mathrm{d}_{\mathrm{DK}} \\
& \mathrm{a}_{\mathrm{MD}}<\mathrm{b}_{\mathrm{MD}} \leq \mathrm{c}_{\mathrm{MD}}<\mathrm{d}_{\mathrm{MD}} \\
& \mathrm{a}_{\mathrm{BR}}<\mathrm{b}_{\mathrm{BR}} \leq \mathrm{c}_{\mathrm{BR}}<\mathrm{d}_{\mathrm{BR}} \\
& \mathrm{a}_{\mathrm{VBR}}<\mathrm{b}_{\mathrm{VBR}} \leq \mathrm{c}_{\mathrm{VBR}} \leq \mathrm{d}_{\mathrm{VBR}} \\
& \mathrm{c}_{\mathrm{VDK}}<\mathrm{a}_{\mathrm{DK}} \leq \mathrm{d}_{\mathrm{VDK}}<\mathrm{b}_{\mathrm{DK}} \\
& \mathrm{c}_{\mathrm{DK}} \leq \mathrm{a}_{\mathrm{MD}} \leq \mathrm{d}_{\mathrm{DK}}<\mathrm{b}_{\mathrm{MD}} \\
& \mathrm{c}_{\mathrm{MD}} \leq \mathrm{a}_{\mathrm{BR}} \leq \mathrm{d}_{\mathrm{MD}}<\mathrm{b}_{\mathrm{BR}} \\
& \mathrm{c}_{\mathrm{BR}}<\mathrm{a}_{\mathrm{VBR}} \leq \mathrm{d}_{\mathrm{BR}}<\mathrm{b}_{\mathrm{VBR}}
\end{aligned}
$$

These restrictions make the tuning range large to improve the training efficiency for the image knowledge base, but the above restrictions are not suitable to train the membership functions of luminance. The luminance is a variable for the images, it may be VDK, DK, MD, BR or VBR. Thus the linguistic term VDK of the luminance may be located at different gray levels for a different chromosome. By using Adaptive Restriction algorithm, that can solve this problem. The Adaptive Restriction Algorithm for the fuzzy variable luminance is as follows

\section{Adaptive Restriction Algorithm}

Set the Adaptive Restrictions of fuzzy variable luminance for genetic tuning.

Input:

The chromosome from the gene populations.

Output:

The restriction set of the linguistic terms of the luminance.

\section{Method:}

Step 1: Retrieve the parameters of the luminance from the chromosome.

$\begin{aligned} \text { Step 1.1: } & {\left[\mathrm{G}_{\mathrm{VDK}-\mathrm{l}}, \mathrm{G}_{\mathrm{VDK}-\mathrm{hl}}, \mathrm{G}_{\mathrm{VDK}-\mathrm{hr}}, \mathrm{G}_{\mathrm{VDK}-\mathrm{r}}\right] \leftarrow } \\ & {\left[\mathrm{a}_{\mathrm{VDK}}, \mathrm{b}_{\mathrm{VDK}}, \mathrm{c}_{\mathrm{VDK}}, \mathrm{d}_{\mathrm{VDK}}\right] }\end{aligned}$

Step 1.2: $\left[\mathrm{G}_{\mathrm{DK}-\mathrm{l}}, \mathrm{G}_{\mathrm{DK}-\mathrm{hl}}, \mathrm{G}_{\mathrm{DK}-\mathrm{hr}}, \mathrm{G}_{\mathrm{DK}-\mathrm{r}}\right] \leftarrow$ $\left[\mathrm{a}_{\mathrm{DK}}, \mathrm{b}_{\mathrm{DK}}, \mathrm{c}_{\mathrm{DK}}, \mathrm{d}_{\mathrm{DK}}\right]$

Step 1.3: $\left[\mathrm{G}_{\mathrm{MD}-\mathrm{l}}, \mathrm{G}_{\mathrm{MD}-\mathrm{hl}}, \mathrm{G}_{\mathrm{MD}-\mathrm{hr}}, \mathrm{G}_{\mathrm{MD}-\mathrm{r}}\right] \leftarrow$ $\left[\mathrm{a}_{\mathrm{MD}}, \mathrm{b}_{\mathrm{MD}}, \mathrm{c}_{\mathrm{MD}}, \mathrm{d}_{\mathrm{MD}}\right]$

Step 1.4: $\left[\mathrm{G}_{\mathrm{BR}-\mathrm{l}}, \mathrm{G}_{\mathrm{BR}-\mathrm{hl}}, \mathrm{G}_{\mathrm{BR}-\mathrm{hr}}, \mathrm{G}_{\mathrm{BR}-\mathrm{r}}\right] \leftarrow$ $\left[\mathrm{a}_{\mathrm{BR}}, \mathrm{b}_{\mathrm{BR}}, \mathrm{c}_{\mathrm{BR}}, \mathrm{d}_{\mathrm{BR}}\right]$

Step 1.5: $\left[\mathrm{G}_{\mathrm{VBR}-\mathrm{l}}, \mathrm{G}_{\mathrm{VBR}-\mathrm{hl}}, \mathrm{G}_{\mathrm{VBR}-\mathrm{hr}}, \mathrm{G}_{\mathrm{VBR}-\mathrm{r}}\right] \leftarrow$ $\left[\mathrm{a}_{\mathrm{VBR}}, \mathrm{b}_{\mathrm{VBR}}, \mathrm{c}_{\mathrm{VBR}}, \mathrm{d}_{\mathrm{VBR}}\right]$

Step 2: Sort the positions of linguistic terms mountain values

(i.e., $)\left(\mathrm{G}_{\mathrm{VDK}-\mathrm{hl}}+\mathrm{G}_{\mathrm{VDK}-\mathrm{hr}}\right) / 2,\left(\mathrm{G}_{\mathrm{DK}-\mathrm{hl}}+\mathrm{G}_{\mathrm{DK}-\mathrm{hr}}\right) / 2$, $\left(\mathrm{G}_{\mathrm{MD}-h l}+\mathrm{G}_{\mathrm{MD}-\mathrm{hr}}\right) / 2, \quad\left(\mathrm{G}_{\mathrm{BR}-\mathrm{hl}}+\mathrm{G}_{\mathrm{BR}-\mathrm{hr}}\right) / 2$, $\left(\mathrm{G}_{\mathrm{VBR}-\mathrm{hl}}+\mathrm{G}_{\mathrm{VBR}-\mathrm{hr}}\right) / 2$

Step 2.1: min $\leftarrow$ the linguistic term with minimum mountain value

Step 2.2: med-min $\leftarrow$ the linguistic term with med - minimum mountain value
Step 2.3: med $\leftarrow$ the linguistic term with medium -mountain value.

Step 2.4: med $-\max \leftarrow$ the linguistic term with medium maximum mountain value.

Step 2.5: $\max \leftarrow$ the linguistic term with maximum mountain value.

Step 3: Generate the adaptive dynamic restrictions as follows

Step 3.1: Generate the restriction

$$
\mathrm{G}_{\mathrm{min}-\mathrm{l}} \leq \mathrm{G}_{\mathrm{min}-\mathrm{hl}} \leq \mathrm{G}_{\mathrm{min}-\mathrm{hr}} \leq \mathrm{G}_{\mathrm{min}-\mathrm{r}}
$$

Step 3.2: Generate the restriction

$$
\mathrm{G}_{\text {med-min-l }}<\mathrm{G}_{\text {med-min-hl }} \leq \mathrm{G}_{\text {med-min-hr }}<\mathrm{G}_{\text {med-min-r }}
$$

Step 3.3: Generate the restriction

$$
\mathrm{G}_{\text {med-l }}<\mathrm{G}_{\text {med-hl }} \leq \mathrm{G}_{\text {med-hr }}<\mathrm{G}_{\text {med-r }}
$$

Step 3.4: Generate the restriction

$$
\mathrm{G}_{\text {med-max-l }}<\mathrm{G}_{\text {med-max-hl }} \leq \mathrm{G}_{\text {med-max-hr }}<\mathrm{G}_{\text {med-max-r }}
$$

Step 3.5: Generate the restriction

$$
\mathrm{G}_{\text {max-l }}<\mathrm{G}_{\text {max-hl }} \leq \mathrm{G}_{\text {max-hr }} \leq \mathrm{G}_{\text {max-r }}
$$

Step 4: End.

Next, a linguistic modifier used in the image knowledge base is a function with the parameters $\partial$ that alter the membership functions. Two of the most well known modifiers are erosion linguistic modifier "very" $(\partial=2)$ and the dilation linguistic modifier "more or less" $(\partial=0.5)$.

$$
\begin{aligned}
& \mu_{(\mathrm{x})=}^{\text {very }}(\mu(\mathrm{x}))^{2} \\
& \mu^{\text {moreorless }}(\mathrm{x})=(\mu(\mathrm{x}))^{0.5}
\end{aligned}
$$

The initial population for the gene pool is composed of four groups with the same number $\mathrm{cs}_{\mathrm{a}}$ part and $\mathrm{cs}_{\mathrm{b} 1}+\mathrm{cs}_{\mathrm{b} 2}$ part

(1) Composed of original $\mathrm{cs}_{\mathrm{a}}$ part and the original $\mathrm{cs}_{\mathrm{b} 1}+\mathrm{cs}_{\mathrm{b} 2}$

(2) Composed of original $\mathrm{Cs}_{\mathrm{a}}$ part and the randomized $\mathrm{Cs}_{\mathrm{b} 1}+\mathrm{cs}_{\mathrm{b} 2}$ part

(3) Composed of randomized $\mathrm{cs}_{\mathrm{a}}$ part and the original $\mathrm{Cs}_{\mathrm{b} 1}+\mathrm{Cs}_{\mathrm{b} 2}$ part

(4) Composed of randomized $\mathrm{cs}_{\mathrm{a}}$ part and the randomized $\mathrm{cs}_{\mathrm{b} 1}+\mathrm{cs}_{\mathrm{b} 2}$ part

Next, we describe genetic operator as follows: The genetic learning process initiates the population by the encoding schema and restrictions and then records the initial population as the current population. The chromosome in the current population is evaluated by the fitness function. If the evaluation does not suit the fitness function,the genetic learning processes the generation. The elitism is used in the learning process. In the beginning of selection, the best two chromosomes in the current population are selected as a new population without crossover and mutation. After the elitism, we produce other population by means of reproduction, crossover, mutation operators. The one point cross over method is adopted and the crossover point is randomly placed. The mutation process is applied to each offspring after the crossover. In this part, the $\mathrm{cs}_{\mathrm{a}}$ part and $\mathrm{cs}_{\mathrm{b} 1}+\mathrm{cs}_{\mathrm{b} 2}$ part are mutated based on the encoded restrictions of fuzzy variable, binary weight, and the set $\{0.5,1,2\}$ respectively. The objective function $\mathrm{f}$, which measures the fitness of each individual based an Mean 
Absolute Error (MAE) between processed image and the original noise free image.

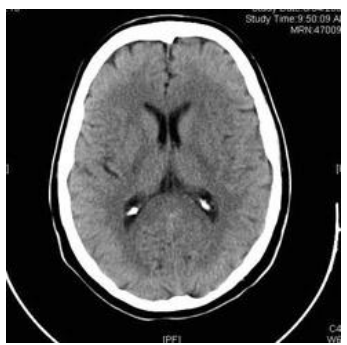

Fig 11) a)

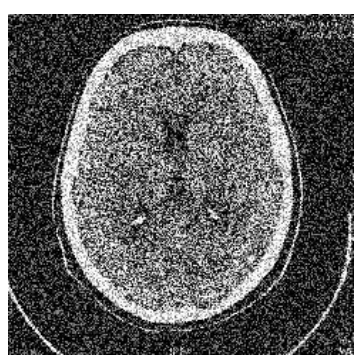

Fig 11) b)

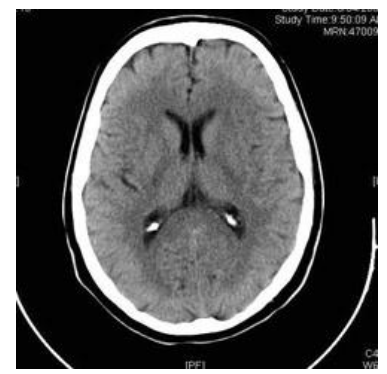

Fig 11) c)

Fig 11. (a) -(c) shows the noise free CT image, noisy CT image with a corruption rate 0.4 and result image by GBFIF respectively.

$$
F=\frac{\sum_{n=1}^{N} \sum_{m=1}^{M}|y(n, m)-s(n, m)|}{N \times M}
$$

Where NxM is the number of processed pixels. The learning process stops when an assigned number of generations has been evolved or when a satisfactory value of fitness has been obtained.

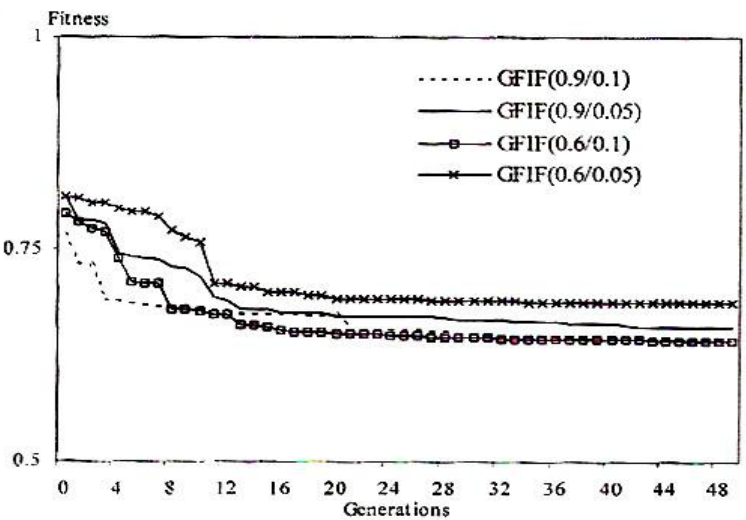

Fig 12 a) Values of fitness obtained during the learning process and effects of

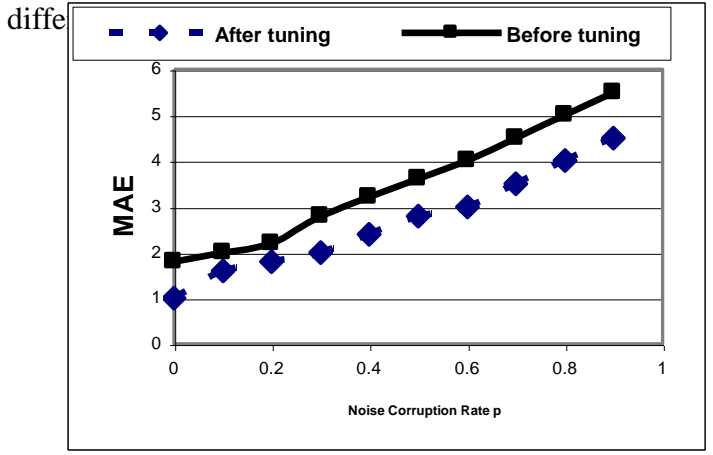

Fig 12 b) MAE curves of GBFIF before turning and after tuning on the CT image corrupted by salt-and-pepper impulse noises with the noise corruption rate $\mathrm{p}$, where $\mathrm{p}=0$ to 0.9 .

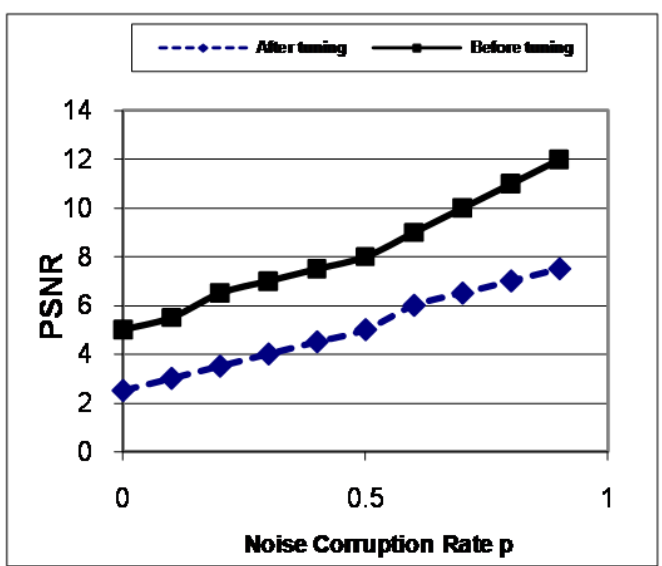

Fig 12 c) MSE curves of GBFIF before turning and after tuning on the CT image corrupted by salt-and-pepper impulse noises with the noise corruption rate $\mathrm{p}$, where $\mathrm{p}=0$ to 0.9 .

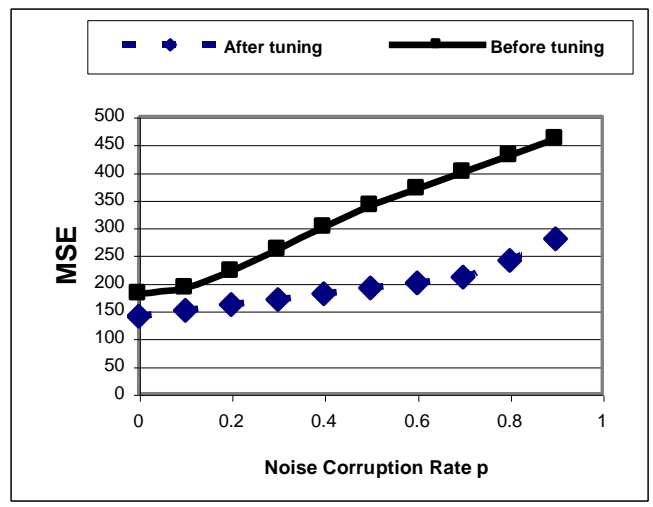

Fig 12 d) PSNR curves of GBFIF before turning and after tuning on the CT image corrupted by salt-and-pepper impulse noises with the noise corruption rate $p$, where $p=0$ to 0.9 


\section{Experimental Results:}

We adopt the CT image to be the sample image for the fuzzy number construction process to construct image knowledge base. In addition, we also produce a salt and pepper noisy CT image with a corruption rate 0.4 for the fuzzy filtering process and genetic learning process. We have chosen a small population of 20 individuals and set the parameters of genetic learning as follows: Cross over probability 0.6 , Mutation rate 0.1 and 50 generations.

Fig. 11(a)-(c) shows the noise free CT image, noisy CT image with a corruption rate of 0.4 and resulting CT image by GBFIF respectively.

Table 1 shows the parameters of fuzzy set constructed by GBFIF for salt and pepper noisy CT image with a corruption rate 0.4. Fig. 12.a. shows the values of fitness obtained during the learning process and effects of choices of genetic parameter for CT image fig.12.(b) shows the MAE curves of GBFIF before tuning and after tuning on the CT image corrupted by salt and pepper noise with the noise corruption rate $\mathrm{p}$ where $\mathrm{p}=0$ to 0.9 . Fig.12.c. shows the MSE curves of GBFIF before tuning and after tuning on the CT image corrupted by salt and pepper impulse noise with the noise corruption rate $\mathrm{p}$ where $\mathrm{p}=0$ to 0.9. Fig.12.d. shows the PSNR curves of GBFIF before tuning and after tuning on the CT image corrupted by salt and pepper impulse noise with the noise corruption rate $\mathrm{p}$ where $\mathrm{p}=0$ to 0.9 .

\section{CONCLUSION}

In this paper, a genetic based, multilayered fuzzy image filter has been presented. GBFIF contains four parts, including a fuzzy number construction process, a fuzzy filtering process, a genetic learning process and an image knowledge base to perform efficient and effective impulse noise removal. The fuzzy number construction process receives sample images or the noise free image and then constructs the image knowledge base for the filter. Then the fuzzy filtering process refers to the fuzzy knowledge base to execute the fuzzy inference. Since it is used to remove noise without degrading image structure, and to preserves the quality of fine details and textures. The genetic learning process adjusts the parameters for fuzzy sets for getting the optimal knowledge base. From the experimental results, based on the criteria of PSNR, MSE, MAE, GBFIF achieve the most effective result than other approaches for removing heavily corrupted additive identical independent distribution impulse noise from highly corrupted images. In the future, we will extend GBFIF to process other medical images.

\section{REFERENCES}

[1] K.Arakawa, "Median filter based on fuzzy rules and its application to image restoration. "Fuzzy Sets Syst., vol. 77, pp.3-13,1996.

[2] S.J.Ko and S.J. Lee, "Center weighted median filters and their applications to image enhancement", IEEE Trans. Circuits Sys., Vol.15, No. 9, pp. 984-993, Sep. 1991.

[3] H.L. Eng and K.K. Ma, "Noise adaptive soft-switching median filter," IEEE Trans, Image Process., Vol. 10,no.2.pp 242-251, Feb.2001

[4] L.Khriji and M.Gabbouj, "Median-rational hybrid filters,' in Proc. Int. Conf. Image Process, Chicago, IL, 1998, pp. 853-857.

[5] E.Abreu and S.K. Mitra, "A signal-dependent rank ordered mean (SD-ROM) filter, "in proc. IEEE Int. Conf. Acoust., Speech, Signal process., Detroit, MI, 1995,pp.2371-2374.

[6] C.S. Lee, Y.H. Kuo, and P.T. yui, "Weighted fuzzy mean filters for image processing "Fuzzy sets Syst., vol.89, pp157-180,1997.

[7] Y.H. Kuo, C.S.Lee, and C-L.Chen, "High-stability AWFM filter for signal restoration and its hardware design," fuzzy Sets Sys., vol. 114,no,2 .pp. 185-202,2000

[8] C.S Lee, Y.d. kuo, "Intelligent fuzzy image filter for impulse noise removal" in proc, IEEE Int. Conf. Fuzzy Syst., Vol. 1, May 2002, pp. 431-436.

[9] F.Russo, "Hybrid neuro-fuzzy filter for impulse noise removal," Pattern Recognition., vol.32, pp.18431855,1999 .

[10] J.H. Wange, Wang, W.J. Liu, and L.D. Lin, "Histogrambased fuzzy filter for image restoration," IEEE Trans. Syst.,Man, Cybern, B, vol.32, no.2, pp.230-238, Apr. 2002.

[11] R.Lukac."Adaptive vector median filtering,", Pattern Recognition Lettters., vol. 24, pp. 1899-1899,2003.

[12] J.Y. Chang and J.L. Chen, "Classified-augmented median filters for image restoration," IEEE Trans, Instrum., meas., vol 53, no.2 pp-351-356, Apr.2004.

[13] O. Cordon, F. Herrera, and P.Villar, "Generating the knowledge base of a fuzzy rule-based system by the genetic learning of the data base," IEEE Trans. Fuzzy Syst., vol. 9, no.4 pp-667-674. Aug 2001. 